\title{
ANÁLISE DE SÍFILIS CONGÊNITA EM UMA MATERNIDADE DE RISCO HABITUAL: RELATO DE EXPERIÊNCIA
}

\begin{abstract}
Karen Ariane Bär ${ }^{1}$; Helena Moro Stochero²; Jucimara Montagner Michelon ${ }^{3}$; Lisiane de Borba Miller ; Luciano Samaniego Arrusul ${ }^{5}$; Regina Celia de Castro Gomes $^{6}$; Regina Gema Santini Costenaro7; Mara Regina Caino Teixeira Marchiori $^{8}$
\end{abstract}

\section{RESUMO}

Objetivo: Relatar a experiência de alunas do curso de Mestrado Materno Infantil apartir da análise do perfil epidemiológico de sífilis congênita do município de Santa Maria e em recém-nascidos de uma maternidade de risco habitual. Metodologia: Trata-se de um relato de experiência, que foi realizado apartir de um estudo retrospectivo descritivo, quantitativo em relação ao perfil epidemiológico de casos de sífilis congênita notificados no município de Santa Maria, RS no período de 2016 a 2019. Resultados: O Relatório de Gestão das Ações de Saúde Anual de 2017 do município apresenta uma série histórica entre os anos de 2011 a 2016 que evidencia o crescimento de sífilis congênita em menores de 1 ano de idade. Conclusões: Este relato de experiência contribui para a qualificação dos serviços prestados, a fim de permitir a análise de dados anterior e planejar ações que causam impacto na linha do cuidado materno infantil.

Palavras-chave: Materno Infantil; Perfil Epidemiológico; Sífilis Congênita;

Eixo Temático: Atenção Integral e Promoção à Saúde (AIPS)

\footnotetext{
${ }^{1}$ Karen Ariane Bär - UFN - bkarenarianebar@gmail.com

2 Helena Moro Stochero - UFN - helenamorostochero@gmail.com

3 Jucimara Montagner Michelon - UFN - enfer.jucimara@gmail.com

${ }^{4}$ Lisiane de Borba Miller - UFN - lisi_enf@yahoo.com.br

${ }^{5}$ Luciano Samaniego Arrusul - UFN - oceanossul@gmail.com

${ }^{6}$ Regina Celia de Castro Gomes - UFN - rcgomes123@yahoo.com.br

${ }^{7}$ Regina Gema Santini Costenaro - UFN - reginacostenaro@gmail.com

${ }^{8}$ Mara Regina Caino Teixeira Marchiori - UFN - mara.marc@hotmail.com
} 


\section{INTRODUÇÃO}

A sífilis é uma infecção de modo sistêmico, causada pela bactéria Treponema pallidum (T. pallidum), privativa do ser humano, e que, quando não tratada precocemente, pode evoluir para uma enfermidade crônica com seqüelas irreversíveis em longo prazo (BRASIL, 2016).

Conforme o Manual Técnico para o Diagnóstico de Sífilis do Ministério da Saúde (2016), a sífilis, ou LUES, como era conhecido anteriormente, é considerada uma infecção sexualmente transmissível (IST) e, assim, transmitida hegemonicamente pelo contato sexual. O contágio é maior nos estágios iniciais da infecção, o qual se reduz gradativamente conforme ocorre a progressão da doença.

Outra forma de transmissão da infecção é a chamada vertical, que acontece através da placenta durante a gestação, isso ocorre quando a gestante portadora de sífilis não é tratada, ou se nessa ocasião realiza o tratamento de maneira inadequada. A transmissão para o recém- nascido (RN) pode ocorrer com o contato com as lesões genitais durante o parto, contudo é menos frequente (BRASIL, 2012).

Conforme o Ministério da Saúde, o risco de transmissão vertical é muito elevado nas fases primária e secundária da doença, por apresentar carga viral de treponema circulante maior, variando de 90 a 100\%. Nas fases latente e terciária o risco varia entre 10 e $30 \%$. Contudo, a transmissão será maior quanto mais avançada for a gestação, já que a permeabilidade da barreira placentária aumenta com a idade gestacional (BRASIL, 2019).

Corroborando ao tema, o Ministério da Saúde (2019), nas notificações compulsórias, considera caso de sífilis congênita toda criança, ou aborto, ou natimorto de mãe com evidência clínica para a infecção e/ou com sorologia não treponêmica reagente para sífilis com qualquer titulação, na ausência de teste confirmatório, realizada no pré-natal ou no momento do parto ou curetagem, que tenha sido tratada ou tenha recebido tratamento inadequado.

Para Rafalle et al., (2016), a sifilis congênita não tratada ou tratada inadequadamente pode ocasionar complicações tanto precoces quanto tardias, como prematuridade, baixo peso, danos neurológicos, comprometimento auditivo, 
oftalmológico, neurológico e déficit no desenvolvimento neuropsicomotor. Além disso, é responsável por mais de $50 \%$ de morte intrauterina sob a forma de aborto, natimorto e óbito neonatal.

Embora a Sífilis Congênita seja uma doença de notificação compulsória no Brasil desde 1986 (Portaria n 542, de 22/12/86 - Ministério da Saúde), dados do Boletim Epidemiológico de Sífilis publicado em junho de 2019 pelo Ministério da Saúde, indicam aumento no número de casos de sífilis em todo o país e em todos os cenários da infecção.

O número de casos de sífilis congênita em menores de um ano de idade foi de 21.188 em 2016, 24.668 em 2017 e 26.219 em 2018 e 11.759 em 2019. Já o número de óbitos por sífilis congênita foi de 195 casos em 2016 , 222 em 2017 e 241 em 2018. Já no Estado do Rio Grande do Sul, foi notificado Sífilis Congênita em menores de um ano com 1.863 no ano de 2016, 2.022 em 2017, 1.968 em 2018 e 858 em 2019.

Portanto, a crescente incidência serve de alerta para a necessidade de ser realizado um pré-natal de excelência, bem como o tratamento adequado tanto da paciente quanto do parceiro durante o pré-natal, visando evitar sequelas ao recémnascido, juntamente com o objetivo de contribuir para que os casos de Sífilis Congênita inicie um decréscimo.

Desta forma, este estudo traz como objetivo, relatar a experiência de alunas do curso de Mestardo Materno Infantil apartir da análise do perfil epidemiológico de sífilis congênita do município de Santa Maria e em recém-nascidos de uma maternidade pública de risco habitual, do referido município do ano de 2016 a 2019.

Para a copilação destes dados, foram extraídos informações do Sistema de dados do Departamento de Doenças de Condições Crônicas e Infecções Sexualmente Transmissíveis da Secretaria de Vigilância em Saúde disponíveis via sistema de informações de saúde (TABnet) do Sistema de Agravos de Notificação (SINAN), Bi saúde. 


\section{METODOLOGIA}

Trata-se de um relato de experiência, que foi realizado a partir de um estudo retrospectivo descritivo, quantitativo em relação ao perfil epidemiológico de casos de sífilis congênita notificados no município de Santa Maria, Rio Grande do Sul através dos dados do Departamento de Doenças de Condições Crônicas e Infecções Sexualmente Transmissíveis da Secretaria de Vigilância em Saúde disponíveis via sistema de informações de saúde (TABnet) do Sistema de Agravos de Notificação (SINAN), Bi saúde e dados do Controle de Infecção relacionado a Assistência à Saúde no ano de 2019.

O estudo foi desenvolvido com base no relatório dos anos de 2016 até 2019 do referido sistema.O município de Santa Maria-RS é um município localizado na região central do Rio Grande do Sul com uma população estimada de 282,123 mil habitantes e um território de $1.781,566 \mathrm{~km}^{2}$ de acordo com os dados do IBGE estimado para 2019.

As variáveis analisadas foram: número de casos de sífilis congênita, idade da criança, diagnóstico final, faixa etária da mãe, nível de escolaridade da mãe, realização de pré-natal, momento de diagnóstico materno, esquema de tratamento da mãe e presença de tratamento no parceiro da mãe. Os dados obtidos por meio da coleta foram expressos em frequência absoluta e relativa (\%) e analisados utilizando o software Office Excel 360.

\section{RESULTADOS E DISCUSSÕES}

O Relatório de Gestão das Ações de Saúde Anual de 2017 do município de Santa Maria no Rio Grande do Sul apresenta uma série histórica entre os anos de 2011 a 2016 que evidencia o crescimento dos novos casos de sífilis congênita em menores de 1 ano de idade. O número de casos em 2011 foi de 17, em 2012 foi de 30, em 2013 de 32, em 2014 de 34, 2015 de 62 e 2016 de 61 percebe-se neste ano de 2015 e 2016 o número quase dobrou. Este mesmo relatório impõe que a meta anual do município é de 60 casos. 
No relatório supracitado é possível encontrar o número de casos de sífilis gestacional e sífilis congênita em menores de um ano para o ano de 2017 que foram respectivamente: 104 e 68. Quando analisado a porcentagem da infecção congênita sobre a gestacional, isto representa $65,38 \%$.

O mesmo Relatório foi publicado pelo município nos anos conseguintes sendo representados a seguir: Em 2018 a sífilis gestacional foi notificada 145 vezes e a sífilis congênita 73, tornando 50,34\%; em 2019 foram 180 casos de sífilis gestacional e 77 de sífilis congênita, representando 42,78 \%. No primeiro quadrimestre de 2020 foram 36 casos de sífilis gestacional para 17 de sífilis congênita, gerando 47,22\%. Desta forma, quando analisados os mesmos dados em relação a uma maternidade de risco habitual na cidade supracitada, observou-se o aumento gradativo de novos casos de sífilis congênita, até o ano de 2019.

\section{CONCLUSÃO}

A sífilis congênita se tornou um problema de Saúde Pública de grande relevância e que está cada vez mais se destacando no cenário epidemiológico global. Anualmente é notável o aumento dos casos deste agravo onde as limitações nos neonatos são de gravidades significativas e devem ser evitadas ao máximo.

Partindo disso, se observa a necessidade de reforçar as ações e serviços de educação e acompanhamento pré-natal, com foco na elaboração de ações que visem buscar as gestantes na comunidade e acompanhar o ciclo gravídicopuerperal. Portanto, torna-se imprescendível reforçar a importância do tratamento dos companheiros, de forma a não medir esforços para aumentar a eficiência deste serviços e diminuir os índices de infecção congênita por sífilis.

Desta forma, este relato de experiência contribui para a qualificação dos serviços prestados, a fim de permitir a análise de dados anterior e planejar ações que causam impacto na gestão do cuidado materno infantil. 


\section{QUFN}

\section{REFERÊNCIAS}

BRASIL. Ministério da Saúde. Atenção ao pré-natal de baixo risco / Ministério da Saúde. Secretaria de Atenção à Saúde. Departamento de Atenção Básica. Brasília: Editora do Ministério da Saúde, 2012.

BRASIL. Ministério da Saúde. Gabinete do Ministro. Portaria no 2.012, de 19 de outubro de 2016. Aprova o Manual Técnico para o Diagnóstico da Sífilis e dá outras providências. Diário Oficial da União, Poder Executivo, Brasília, DF, no 202, Seção 1, p. 25 . out. 2016

BRASIL. Ministério da Saúde. Portaria n 542, de 22 de dezembro de 1986. Diário Oficial da República Federativa do Brasil. Brasília, DF, 24 dez. 1986, Seção 1, p. 1987.

BRASIL. Ministério da Saúde. Protocolo Clínico e Diretrizes Terapêuticas para Prevenção da Transmissão Vertical de HIV, Sífilis e Hepatites Virais / Ministério da Saúde, Secretaria de Vigilância em Saúde, Departamento de Vigilância, Prevenção e Controle das Infecções Sexualmente Transmissíveis, do HIVIAids e das Hepatites Virais. - Brasília: Ministério da Saúde, 2019.

BRASIL. Ministério da Saúde. Indicadores e Dados básicos da Sífilis nos Municípios Brasileiros. 2019. Disponível em: http://indicadoressifilis.aids.gov.br/. Acesso em: 13 de set. 2019 .

RAFALLE, A, M. et al. As principais complicações da Sífilis Congênita: revisão integrativa de literatura. Revista Saúde. v. 10, n.1 (ESP),p.43. 2016. 